\title{
Editorial
}

\section{From Editor-in-Chief: Peer-review experience at the Heart, Vessels and Transplantation}

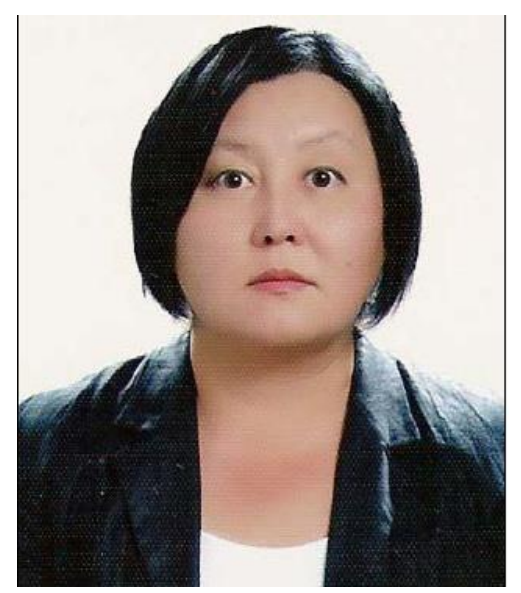

Peer review, process that warrants quality and improvement of scientific work, is the critical evaluation of content of manuscripts submitted to journals by experts in the field of the topic of the manuscript (1-7). The history of peer-review of journal's manuscripts expands back to 3 centuries ago, when for the first time the editorial peer-review was applied and since $19^{\text {th }}$ century it has evolved to use opinions of external expert reviewers (6-9).

The key participants of peer-review process are editors, reviewers and authors. There are two main types of peer-review according to the exposure of peer-review participants identities: closed (single-blind, doubleblind) and open review $(6,7)$. New types of peer-review based on timing related to publication have emerged during recent years: pre-publication peer-review and post-publication peer-review $(6,7,10,11)$.

The most widely used model of peer-review is the single-blind peer-review where the names of reviewers are concealed and remain anonymous to authors, while latter's ones names and affiliations, institute's where the study was performed are exposed to reviewers. In double-blind model, both authors' names, including their affiliations and institutions and reviewers ' names are concealed. In open review, the identity of the authors and reviewers are public, the review reports might be published openly (12), or reviewers and authors may interact with each other -post-publication peer-review $(10,11)$.

Each type of peer-review process has its advantages and disadvantages $(6,7,10)$. The main disadvantage is potential bias pertinent to single-blind and open-review $(6,7,10)$. Open -review has been shown to improve peer-review report and reduced rejection rate by $44 \%$ (13), but has disadvantages of various forms of potential bias (7). Open review with publishing of report was associated with reduced proportion of reject and major revision decisions, and increase in minor revision and accept decisions, however only $8.1 \%$ of reviewers agreed to publish their names and review reports (14). Double-blind peer-review judgment is usually based on content, it is objective and not biased, and is associated with high satisfaction rates of authors, reviewers and editors $(7,10)$. It is worth mentioning that number of problematic retracted papers was significantly lower in double-blind peer-review as compared to single- blind review (11).

Address for Correspondence: Gulmira Kudaiberdieva, Heart, Vessels and Transplantation

Email: editor@hvt-journal.com

Received: 9.03.2020 Accepted: 10.03.2020

Copyright (c) 2019 Heart, Vessels and Transplantation

doi: $10.24969 /$ hvt.2020.190 
Manuscripts submitted for consideration for publication in the Heart, Vessels and Transplantation journal undergo unbiased double-blind (authors', editors', reviewers' names or their institutions, cities and countries of origin are not disclosed in manuscripts; all authors, editors, reviewers participating in peer-review process are blinded) peer-review by editors and external international reviewers (usually 2 , but in case of disparate opinions, 3rd reviewer is invited), experts on the topic of the submitted manuscript.

Editor-in-Chief sends manuscripts after receipt, for initial review to section editors, who return manuscript to editor within 1 week with recommendation and suggest reviewers for the manuscript.

External reviewers are also selected from experts with published works in journals indexed in international databases. The reviewers are informed on the principles of unbiased approach, confidentiality of manuscripts sent for review, timeliness of fulfilling reviewer assignment and quality of report. Reviewers are responsible to disclose any type of conflict of interest and decline to review manuscript in its presence: awareness of the submitted research/case report and authors or their institutions as well, not to use confidential data presented in manuscript in their any current or future own projects and publications. The journal provides the standard reviewer form to be filled by reviewers, including the recommendations for authors and report for editors. Reviewers of the manuscripts are kept informed on co-reviewers reports in blind manner and final editor's decision on manuscript. The average duration of article peerreview evaluation by reviewers is 2 weeks.

Research articles and brief reports, meta-analyses and systematic reviews undergo evaluation by statistics editor of the journal.

After receipt of editors', external independent reviewers' and statistics editor's recommendations, Editor-in-Chief makes decision based on the section editors' advice and reviewers' reports: accept for publication, accept with minor revision, major revision, re-submit and reject. In cases of decisions, accept with minor revision or major revision, resubmit decisions authors are required to submit the revised according to the recommendations of editors ' and reviewers' manuscript, highlighting applied changes, list of responses to comments and list of changes and accompanying letter to the editor within 3 weeks of receiving decision letter.

Editor of the journal carries responsibility for the content of the journal and has right to reject article on any step of evaluation after submission and peer-review in presence of any type of scientific or ethical misconduct. The articles might also be rejected after "in-house" review by editor and section editors on priority basis or when submitted work is out of scope of the journal; the work is returned to authors with recommendation of submission to other journals.

Editors of the journal do not exercise policy to reject manuscripts with negative or inconclusive results of the study, as both types of research with well-explained rationale and design might contribute to current scientific evidence and may be used in systematic reviews and meta-analyses.

We analyzed peer-review process conducted by editors and external reviewers in Heart, Vessels and Transplantation by availability of invited external experts for review, demographics, international diversity (1), and their recommendation for decision on manuscript and its priority.

Of all invited external expert reviewers, we received response from $59.1 \%$ of reviewers (Fig. 1), of whom $66.6 \%$ agreed to participate in peer-review; $22.2 \%$ were excused as being unavailable for review for different reasons; $11.1 \%$ did not respond for queries further.

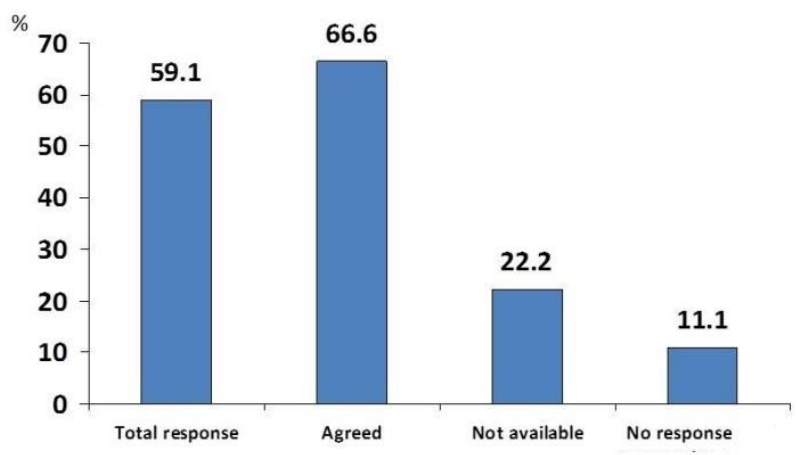

Figure 1. Response of external international reviewers for invitation to review manuscript 
$\%$

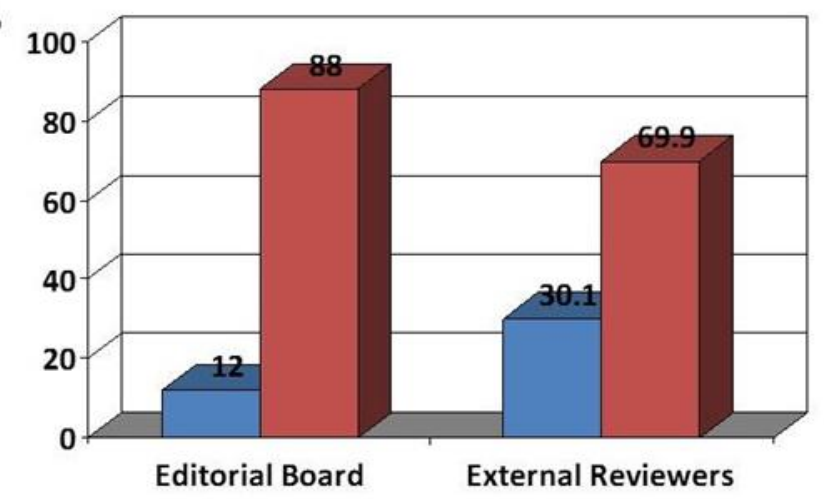

Female $\square$ Male

\section{Figure 2. Distribution of reviewers by gender}

Analysis of demographics showed that, $12 \%$ of manuscript evaluations were performed by female editors and $30.1 \%$ - by female external reviewers, while majority of manuscript evaluations were conducted by male editors and external reviewers (88\% and $60.9 \%$, respectively) (Fig. 2).

International diversity of editors and reviewers participated in peer-review is represented by editors from 15 countries (Australia, Brazil, France, Greece, Monaco, Kazakhstan, Kyrgyzstan, Poland, Slovakia, Spain, Switzerland, Turkey, UK, Ukraine and USA) and external reviewers from 24 countries (Argentina, Australia, Brazil, Canada, Denmark, Germany, Greece, India, Italy, Japan, Kazakhstan, Kyrgyzstan, Monaco, Nepal, Netherlands, New Zealand, Poland, Romania, Russia, South Africa, Sweden, Turkey, UK and USA).

External reviewers' recommendations on peerreviewed manuscripts are distributed as following (Fig. $3)$ accept in $8 \%$, minor revision in $43 \%$, major revision/resubmit in $31 \%$ and reject decisions in $18 \%$ of manuscripts. Reviewers graded manuscript as of low priority in $26 \%$, moderate $-48 \%$ and high priority in $26 \%$ of manuscripts.
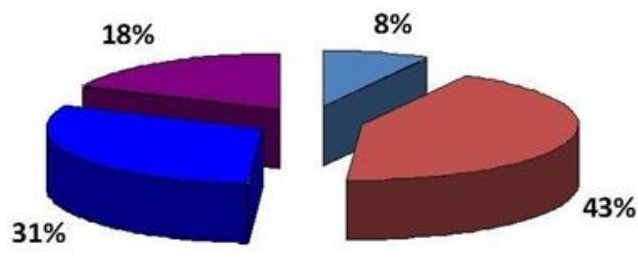

$\square$ Accept

$\square$ Minor revision

- Major revision, resubmit $\quad$ Reject

A

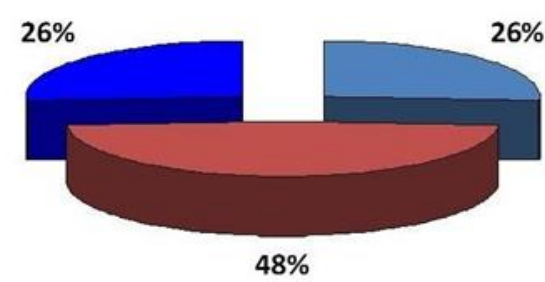

Low $\square$ Moderate $\square$ High

Figure 3. Recommendations of external reviewers $(A)$ and grading of priority of manuscripts (B) 
We would like to thank once more all reviewers and editors participated in peer-review of manuscripts for Heart, Vessels and Transplantation journal.

We will continue improving art of peer-review in the journal.

Gulmira Kudaiberdieva

Editor-in-Chief

Heart, Vessels and Transplantation

Peer-review: Internal

Conflict of interest: None to declare

Authorship: G.K.

Acknowledgement: None to declare Funding: None to declare

\section{References}

1.Recommendations for the Conduct, Reporting, Editing, and Publication of Scholarly Work in Medical Journals. Updated December 2019. Available at: URL: www.icmje.org.

2.Hames I. on behalf of COPE Council. COPE Ethical Guidelines for Peer Reviewers. Available at: URL.www. publicationethics.org

3.Scott-Lichter D and the Editorial Policy Committee, Council of Science Editors. CSE's White Paper on Promoting Integrity in Scientific Journal Publications, 2012 Update. 3rd Revised Edition. Wheat Ridge, CO: 2012. Available at: URL: www.councilscienceeditors.org. Accessed on 09.01.2017.

4.NLM's Research Reporting Guidelines and Initiatives: (www.nlm.nih.gov/services/research_report_guide.htm I).
5.COPE: Committee on publication ethics. Code of conduct and best practice guidelines for journal editors. 2011. Available at URL: www.publicationethics.org 6. Horbach SPJM, Halffman W. The changing forms and expectations of peer review. Research Integrity and Peer Review 2018; 3: 8.

7. Manchikanti L, Kaye AD, Boswell M, MD, Hirsch J.A. Medical journal peer review: process and bias. Pain Phys 2015; 18: E1-E14.

8. Kronick DA. Peer review in 18th-century scientific journalism. JAMA 1990; 263: 1321-2.

9. Burnham JC. The evolution of editorial peer review. JAMA 1990; 263: 1323-9.

10. Azam Ali PA, Watson R. Peer review and the publication process. Nursing Open 2016; 193-202.

11. Horbach SPJM, W. Halffman W. The ability of different peer review procedures to flag problematic publications. Scientometrics 2019; 118: 339-373. https://doi.org/10.1007/s11192-018-2969-2

12. Beck J, Funk K, Harrison M, McEntyre J, Breen J, Collings $A$, et al. Publishing peer review materials [version 1; referees: 2 approved]. F1000Research 2018, 7: 1655.

13. Bruce R, Chauvin A, Trinquart L, Ravaud P, Boutron I. Impact of interventions to improve the quality of peer review of biomedical journals: a systematic review and meta-analysis. Bruce et al. BMC Medicine 2016; 14: 85.

14. Bravo B, Grimaldo F, Emilia Lopez-Inesta E, Mehmani B, Squazzoni F. The effect of publishing peer review reports on referee behavior in five scholarly journals. Nature Communications 2019; 10: 322. https://doi.org/10.1038/s41467-018-08250-2 